\title{
Technology in the Employment Interview: A Meta-Analysis and Future Research Agenda
}

\author{
Nikki Blacksmith \\ The George Washington University \\ Jon C. Willford \\ The George Washington University \\ Tara S. Behrend \\ The George Washington University
}

Follow this and additional works at: https://scholarworks.bgsu.edu/pad

Part of the Communication Technology and New Media Commons, Human Resources Management Commons, Industrial and Organizational Psychology Commons, and the Other Psychology Commons How does access to this work benefit you? Let us know!

\section{Recommended Citation}

Blacksmith, Nikki; Willford, Jon C.; and Behrend, Tara S. (2016) "Technology in the Employment Interview: A Meta-Analysis and Future Research Agenda," Personnel Assessment and Decisions: Number 2 : Iss. 1 , Article 2.

DOI: https://doi.org/10.25035/pad.2016.002

Available at: https://scholarworks.bgsu.edu/pad/vol2/iss1/2

This Main Article is brought to you for free and open access by the Journals at ScholarWorks@BGSU. It has been accepted for inclusion in Personnel Assessment and Decisions by an authorized editor of ScholarWorks@BGSU. 


\title{
TECHNOLOGY IN THE EMPLOYMENT INTERVIEW: A META-ANALYSIS AND Future Research Agenda
}

\author{
Nikki Blacksmith $^{1}$, Jon C. Willford ${ }^{1}$, and Tara S. Behrend ${ }^{1}$
}

1. The George Washington University

\section{KEYWORDS}

employment interviews, technology-mediation, computer-mediated communication, meta-analysis

ABSTRACT

The use of technology such as telephone and video has become common when conducting employment interviews. However, little is known about how technology affects applicant reactions and interviewer ratings. We conducted meta-analyses of 12 studies that resulted in $K=13$ unique samples and $N=1,557$. Mean effect sizes for interview medium on ratings $(d=-.41)$ and reactions $(d=-.36)$ were moderate and negative, suggesting that interviewer ratings and applicant reactions are lower in technology-mediated interviews. Generalizing research findings from face-to-face interviews to technology-mediated interviews is inappropriate. Organizations should be especially wary of varying interview mode across applicants, as inconsistency in administration could lead to fairness issues. At the same time, given the limited research that exists, we call for renewed attention and further studies on potential moderators of this effect.

To reduce costs, reach a more globalized labor market, and implement environmentally sustainable practices, organizations use technologies such as telephone, video, or online chat to conduct employment interviews (Andrews, Klein, Forsman, \& Sachau, 2013; Behrend \& Thompson, 2013). Although organizations have embraced the use of these technologies, research examining how interview medium influences applicant behaviors is underdeveloped. Technology may unintentionally affect the validity and reliability of the interview, introduce systematic sources of variance (Howard \& Ferris, 1996; Potosky, 2008), and/or create bias. Thus, the goal of this paper is to conduct a meta-analysis to systematically understand effects of technology mediation on interviewers and interviewees. Further, we use these findings to call for future research to develop a more comprehensive understanding of how technology affects interview outcomes.

\section{Impression Management and Technology-Mediation}

Applicants intentionally and strategically use impression management techniques in face-to-face (FTF) interviews because they believe it increases their chances of being perceived as viable candidates (Gilmore \& Ferris, 1989). Impression management refers to a set of behavioral techniques (e.g., patterns of speech, nonverbal behaviors, visual cues) applicants use to influence interviewers' per- ceptions (Ellis, West, Ryan, \& DeShon, 2002; Stevens \& Kristof, 1995). Impression management tactics are successful, in that they increase interviewers' ratings (Barrick, Shaffer, \& DeGrassi, 2009; Rosenfeld, 1997; Stevens \& Kristof, 1995). However, applicants in technology-mediated interviews may not be able to impression manage as they would in FTF interviews.

Extant research demonstrates that seemingly innocuous features of technology can be a force of situational strength that impedes impression management tactics (Blackman, 2002). The way in which technology impedes impression management will differ across technology type, but all technology-mediated interviews have some degree of impediment. In telephone interviews, all nonverbal cues are removed, and therefore applicants cannot adjust their responses based on the interviewers' facial cues. There is also potential that poor connections interrupt communication. In video-based interviews, verbal communication can be frustrating as there may be a time lag (Wegge, 2006). A pic-

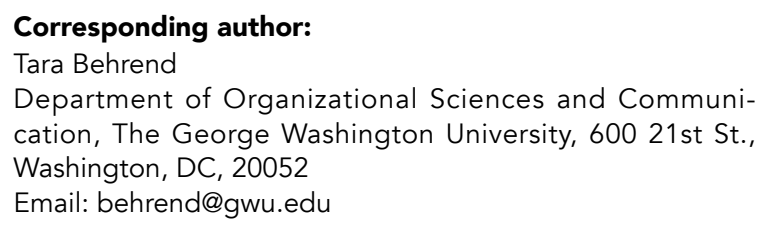

The authors would like to thank to Max Silverman for his assistance with data collection.

They would also like to thank Samuel E. Kaminsky and the WAVE lab for providing insightful feedback and suggestions on previous drafts of this paper. 
ture-in-picture option may elicit negative affective reactions (Horn \& Behrend, 2016). Additionally, applicants' social skills can be misinterpreted because eye contact is difficult due to camera angles. In computer-mediated or interactive voice response (IVR) interviews, applicants may not have the opportunity to ask for clarification. Similar to a telephone interview, they cannot see the interviewer and adjust responses accordingly.

This is concerning, as applicants rely on impression management techniques to maintain control of how they are perceived by interviewers. Further, impression management has been positively linked to job performance, which suggests it is a valuable workplace skill (Ingold, Kleinmann, König, \& Melcher, 2015). Hindrance of impression management may decrease interviewer ratings, as interviewers draw from these cues to evaluate candidates. Further, restriction of these behaviors may lead applicants to become frustrated with limitations in positively swaying the interviewers' rating and consequently react negatively to the interview. As such, we focus on interviewer ratings and applicant reactions as the two outcomes of interest in this study, discussed in more detail below.

Interviewer ratings. Technology-mediation restricts the interviewers' ability to observe nonverbal behavior and other rich cues, which includes impression management tactics (Barrick et al., 2012; Chapman \& Rowe, 2001). Removal of these cues could influence how interviewers draw inferences and in turn either increase or decrease interviewers' ratings (Chapman \& Rowe, 2001; DeGroot \& Motowidlo, 1999; Howard \& Ferris, 1996). Further, the change in context may cause a change in applicants' behavior, which could directly influence ratings (Potosky, 2008). From one perspective, it is possible the use of technology-mediation will increase ratings as it may reduce interviewee anxiety by removing pressure associated with an in-person interview (Chapman \& Rowe, 2001). However, prior research (e.g., Shermis \& Lombard, 1998; Wegge, 2006) indicates that the use of technology media in selection procedures can introduce anxiety. Thus, it is most likely that the use of technology in the interview decreases ratings.

There are many reasons why interviewers are likely to rate applicants more negatively in technology-mediated interviews. First, impression management signals provide clarity to ambiguous comments; removal of these signals may lead to misunderstanding and in turn harm ratings. Technology can also lead to poor perceptions of interpersonal skills. Telephone communication removes all visual cues, which hinders socio-emotional dimensions of interaction (Walther, 2012). For example, interviewees cannot read the facial expressions of the interviewers and adapt their responses as a means of ingratiation, nor can they smile or create other nonverbal personal connections. Ratings are also likely to be lower because the rapport-building stage is shorter in a technology-mediated interview; good impres- sions during this stage positively influence subsequent interviewer ratings (Barrick et al., 2012). In a FTF interview, there is a block of time between the moment the interviewee meets the interviewer and when the interview begins (e.g., walking from the lobby to interview location), which is not present in technology-mediated interviews.

The removal or limited view of nonverbal behaviors can also negatively influence ratings, as they are linked to perceptions of intelligence (Borkenau \& Liebler, 1995; Larsen \& Shackelford, 1996). In some video-based communication technologies, the restricted camera view can limit observation of nonverbal behaviors (e.g., hand gestures, eye contact), changing the pace of the conversation and social interaction (Blackman, 2002; Chapman \& Rowe, 2001; 2002; DeGroot \& Gooty, 2009). These changes can harm ratings as halting one's speech and gaze aversion are linked to perceptions of lower intelligence (Borkenau \& Liebler, 1995; Larsen \& Shackelford, 1996). Last, as mentioned previously, applicants are likely to experience anxiety in technology-mediated interviews, which can lower ratings because anxious interviewees receive lower ratings (Feiler \& Powell, 2016). When applicants are motivated to make positive impressions but believe they will not succeed because of the limitations placed on them, they experience anxiety (Giordano, Stoner, DiGangi, \& Lewis, 2010; Leary, 1983; Leary \& Kowalski, 1990).

In sum, technology-mediated interviews hinder socio-emotional interactions, which likely lowers perceptions of applicants' social skills. The way technology affects perceptions of behaviors, such as eye gaze, can also lead to lower attributions of qualifications. This should lead to lower ratings.

Hypothesis 1: Interviewer ratings will be lower in technology-mediated interviews compared to FTF interviews.

Applicant reactions. Technology characteristics can influence how applicants perceive the selection process, the interviewer, and the organization, leading to a range of consequences such as intent to accept an offer, recommend the organization, and/or file a lawsuit (Chapman, Uggerslev, Carroll, Piasentin, \& Jones, 2005; Hausknecht, Day, \& Thomas, 2004; Rynes \& Connerley, 1993).

Several features and attributes in technology-mediated interviews may be responsible for negatively influencing applicant reactions (DeGroot \& Gooty, 2009; Doherty-Sneddon et al., 1997; Swider, Barrick, Harris, \& Stoverink, 2011). As mentioned above, removal of visual and audio cues, which are present in FTF interviews, may make an applicant feel less free to impression manage. Telephone interviews only allow audio communication, which prevents applicants from using nonverbal techniques such as smiling, professional presence (Chapman, Uggerslev, \& Webster, 2003; Straus, Miles, \& Levesque, 2001), or handshakes (Stewart, Dustin, Barrick, \& Darnold, 2008). With- 
out visual feedback from the interviewer, applicants may be unsure of how their performance in the interview is being received, further decreasing their ability to impression manage and potentially shaking their confidence. Depending on the quality of the Internet connection available and factors such as computer quality, video-based interviews also have potential for lag times, which result in awkward communication exchanges (Powers, Rauh, Henning, Buck, \& West, 2011; Toldi, 2011). These constraints may also negatively influence perceptions of procedural fairness (Guchait, Ruetzler, Taylor, \& Toldi, 2014). Further, applicants' perceptions that they did not receive an adequate chance to perform can lead to feelings of frustration or exertion of more energy to communicate with interviewers (Bauer, Truxillo, Mack, \& Costa, 2011; Chapman et al., 2003).

In sum, we argue that technology-mediated interviews should negatively affect applicant reactions to the interview process. The change in context restricts applicants' ability to engage in impression management behaviors, likely leading applicants to feel frustrated or as if they lacked the chance to perform. Finally, the very choice to conduct an interview via technology may lead applicants to feel less valued, further decreasing reactions.

Hypothesis 2: Applicant reactions to technology-mediated interviews will be less favorable than FTF interviews.

\section{Potential Moderators}

There are a number of potential moderators that could influence the relationship between interview medium and outcomes. First, the type of technology is likely a moderator. Each technology type varies in the extent to which it can transmit verbal, nonverbal, and other communication cues (Maruping \& Agarawal, 2004). Interview structure has also been shown to moderate this relationship. Chapman and Rowe (2002) found that applicants were more satisfied with their performance in unstructured FTF interviews but more satisfied with their performance in structured video-based interviews. Because technology changes over time and the use of technology has also been increasing, publication date is a likely moderator. Last, we consider the setting of the research, laboratory or field. Simulated interviews may lack the emotional and cognitive fidelity of field interviews (Posthuma, Morgeson, \& Campion, 2002).

\section{METHOD}

In order to locate studies, a computer-based literature search of PsycINFO, Academic Search Complete, Academic Search Premier, Business Source Complete, Business Source Premier, and Communication \& Mass Media Complete was conducted. Various combinations of the following keywords were used to identify relevant articles, providing 23 empirical articles: interview, selection, employment, vid- eo, videoconferencing, telephone, virtual, online, chat, computer-mediated, e-HR systems, electronic, and technology. References of the 23 articles were reviewed. We identified two additional studies. A manual search of the following journals: Journal of Applied Psychology, Personnel Psychology, International Journal of Selection and Assessment, International Journal of Human-Computer Interaction, and Journal of Computer-Mediated Communication from 1992-2012 was also conducted. No additional articles were found.

Next, we searched all available electronic conference programs of Academy of Management (1996-2012) and Society for Industrial and Organizational Psychology (1992-2012). We found four eligible studies. We conducted a hand search of printed conference programs from the National Communication Association (2008-2012). No presentations met our criteria. We conducted an electronic search of dissertations. Four eligible dissertations were obtained. To gather unpublished studies, we emailed experts in these areas. One author provided two studies. Last, we conducted a standard Internet search. No studies were found. In total, the search effort yielded 31 possible studies.

For inclusion, each article had to contain a comparison between a technology-mediated and FTF interview. Included in this study were seven telephone, five videoconference, one computer-mediated, and two IVR interviews. Interview was defined as an evaluative, synchronous interaction with two parties (e.g., human, computer agent). Interview types included employment interviews, an evaluative research interview, and language skills interviews. Studies using interviews for a purpose other than evaluation were excluded. For example, some studies used interviews to collect qualitative, informative data (e.g., Herman, 1977). Twelve articles met our inclusion criteria resulting in $K=13$ unique samples with a sample size of $N=1,557$. Table 1 provides characteristics of each primary study used.

Two PhD students coded each article; interview medium was the independent variable $(0=F T F, 1=$ technology mediated). Ratings and applicant reactions were coded as dependent variables. Ratings included overall ratings as well as specific ratings of skills, abilities, competencies, talkativeness, conversation fluency, expressiveness, and likeability. Applicant reactions included selection procedural justice, perceived fairness, litigation intentions, expectancy of a favorable outcome, perceived difficulty, satisfaction with performance, ratings of the interviewer, intention to pursue/accept, organizational attractiveness, conversation fluency, self-consciousness, comfort, and concerns about technology. Moderators coded included publication date, technology type, and study setting (i.e., laboratory or field). Few studies reported sufficient details regarding interview structure. The initial agreement between raters was $92 \%$, with differences in coding attributed to misspecification of relevant variables (e.g., whether to define a variable as a 
TABLE 1.

Study Characteristics and Effect Sizes

\begin{tabular}{|c|c|c|c|c|c|c|}
\hline Article & $N$ & $d$ & Technology & Interview type & Participants & Setting \\
\hline \multicolumn{7}{|l|}{ Interviewer ratings } \\
\hline Bauer et al. (2004) & 133 & -0.08 & IVR & Employment & Students & $\mathrm{Lab}$ \\
\hline Blackman (2002) & 57 & -0.52 & TI & Employment & Students & $\mathrm{Lab}$ \\
\hline Chapman \& Rowe (2001) & 25 & 0.45 & $\mathrm{VC}$ & Employment & Student applicants & Field \\
\hline Fullwood (2007) & 24 & -1.53 & $\mathrm{VC}$ & Evaluative research & Students & $\mathrm{Lab}$ \\
\hline Silvesteret al. (2000) & 70 & -0.96 & TI & Employment & Student applicants & Field \\
\hline Silvester \& Anderson (2003) & 57 & 0.05 & TI & Employment & Student applicants & Field \\
\hline Straus et al. (2001) & 60 & 0.04 & $\mathrm{TI} / \mathrm{VC}$ & Employment & Students & Lab \\
\hline Thompson \& Surface (2006) - Sample 1 & 32 & -1.03 & TI & Oral proficiency & Military personnel & Field \\
\hline Thompson \& Surface (2006) - Sample 2 & 52 & -1.12 & TI & Oral proficiency & Military personnel & Field \\
\hline Thompson, Surface, \& Whelan (2007) & 99 & -0.56 & $\mathrm{CM}$ & Oral proficiency & Employees & Field \\
\hline Thompson et al. (n.d.) & 54 & 0.01 & $\mathrm{CM}$ & Employment & Student & Lab \\
\hline \multicolumn{7}{|l|}{ Applicant reactions } \\
\hline Bauer et al. (2004) & 133 & -0.73 & IVR & Employment & Students & $\mathrm{Lab}$ \\
\hline Chapman \& Rowe (2002) & 92 & -0.48 & $\mathrm{VC}$ & Employment & Student applicants & Field \\
\hline Chapman et al. (2003) & 802 & -0.29 & $\mathrm{TI} / \mathrm{VC}$ & Employment & Student applicants & Field \\
\hline Straus et al. (2001) & 60 & -0.47 & $\mathrm{TI} / \mathrm{VC}$ & Employment & Students & Lab \\
\hline Thompson et al. (unpublished) & 54 & -0.24 & $\mathrm{CM}$ & Employment & Students & $\mathrm{Lab}$ \\
\hline
\end{tabular}

Note. $\mathrm{TI}=$ Telephone, $\mathrm{VC}=$ Videoconference, $\mathrm{CM}=$ Computer-mediated, $\mathrm{IVR}=$ Interactive voice response;

Negative effect size $(d)$ indicates more positive reactions to FTF interview.

reaction). After discussion, all discrepancies were resolved. Eleven studies contained interviewer rating data and five contained applicant reaction data.

To conduct the meta-analyses, we used Hunter and Schmidt's (2004) random-effects method using the software developed by Hunter and Schmidt (Schmidt \& Le, 2004). When a study included multiple dependent variables, we created an overall effect and computed a weighted mean effect size in the instances where covariance statistics were not available. When covariance statistics were included, a composite correlation was computed and converted to a $d$ value using the formula given by Hunter and Schmidt (2004). Very few studies included reliability coefficients, therefore, we did not correct for measurement error.

\section{RESULTS}

The meta-analytic effect sizes for interviewer ratings and reactions are presented in Table 2. Hypothesis 1, which stated interviewer ratings would be lower in technology-mediated interviews, was supported $(d=-.41)$. However, credibility intervals included zero, indicating wide-ranging effect sizes and that there are likely moderators. A moderating effect for study setting was found. A larger negative effect was found in field $(d=-.59)$ compared to lab settings $(d=-.22)$. That is, ratings were lower when studies used real interviews. Across technology type, the largest negative effects occurred for video $(d=-.46)$ and telephone $(d=-.46)$ in comparison to computer-mediated interviews $(d=-.35)$.
Publication date also moderated the relationship, however, in the opposite direction as expected. The observed correlation was $-.58, p<.001$ and after correcting for sampling error it was $-.69, p<.001$. The more recent the study, the lower the interviewer ratings (see Figure 1).

The overall effect size $(d=-.36)$ indicates applicant reactions were more favorable in FTF interviews, supporting Hypothesis 2. Contrary to the interviewer rating findings, a larger negative effect was found for lab $(d=-.55)$ than for field $(d=-.31)$. A larger negative effect size was found for video $(d=-.36)$ than telephone interviews $(d=-.26)$. However, it should be noted that estimates of the sampling error were over $100 \%$ for all moderators, indicating that second order sampling error is occurring for these distributions. Thus, results with such high degree of sampling error should be interpreted with caution. Figure 2 presents a visual depiction of the effect of publication date.

\section{DISCUSSION}

This study has contributed to the literature by demonstrating that technology does affect interviewer ratings and applicant reactions. Results indicate ratings are lower in technology-mediated interviews; this may occur for several reasons. Applicants may not be able to demonstrate their social skills when their ability to impression manage is restricted. Ratings could also be lower because applicants' anxiety increases due to frustration or a lack of chance to perform. It is unclear, however, whether change in ratings 
TABLE 2.

Means, Standard Deviations, and Correlations Among Main Variables

\begin{tabular}{|c|c|c|c|c|c|c|c|c|}
\hline $\mathrm{DV}$ & $k$ & $N$ & $d$ & $S D_{w d}$ & $S D_{d}$ & $\%$ variance sampling & $80 \% \mathrm{CV}$ & $95 \% \mathrm{CI}$ \\
\hline \multicolumn{9}{|l|}{ Ratings } \\
\hline Overall & 11 & 663 & -.41 & .48 & .40 & $30 \%$ & $-.92, .11$ & $-.65,-.17$ \\
\hline Field & 6 & 335 & -.59 & .48 & .40 & $32 \%$ & $-1.10,-.08$ & $-.91,-.27$ \\
\hline $\mathrm{Lab}$ & 5 & 328 & -.22 & .40 & .31 & $39 \%$ & $-.62, .18$ & $-.49, .05$ \\
\hline Tele & 6 & 328 & -.46 & .61 & .54 & $21 \%$ & $-1.15, .23$ & $-.89,-.03$ \\
\hline Video & 3 & 109 & -.46 & .64 & .54 & $28 \%$ & $-1.16, .24$ & $-1.07, .15$ \\
\hline $\mathrm{CM}$ & 2 & 153 & -.35 & .27 & .14 & $73 \%$ & $-.53,-.17$ & $-.55,-.16$ \\
\hline \multicolumn{9}{|c|}{ Reactions } \\
\hline Overall & 5 & 1141 & -.36 & .15 & .06 & $82 \%$ & $-.44,-.28$ & $-.41,-.31$ \\
\hline Field & 2 & 894 & -.31 & .06 & .00 & $100 \%^{\mathrm{a}}$ & $-.31,-.31$ & $-.31,-.31$ \\
\hline $\mathrm{Lab}$ & 3 & 247 & -.55 & .20 & .00 & $100 \%{ }^{\mathrm{a}}$ & $-.55,-.55$ & $-.55,-.55$ \\
\hline Tele & 2 & 773 & -.26 & .07 & .00 & $100 \%{ }^{\mathrm{a}}$ & $-.26,-.26$ & $-.26,-.26$ \\
\hline Video & 3 & 824 & -.36 & .05 & .00 & $100 \%^{a}$ & $-.36,-.36$ & $-.36,-.36$ \\
\hline
\end{tabular}

Note. Negative effect size $(d)$ indicates more positive reactions to FTF condition; $d=$ sample size weighted mean effect size; $S D_{w d}=$ sample size weighted standard deviation of observed $d$-values; $S D_{d}=$ standard deviation of $d$-values corrected for sampling error; \% variance sampling = percent variance in observed $d$-values due to sampling error; $\mathrm{CV}=$ credibility interval; $\mathrm{CI}=$ confidence interval.

${ }^{a}$ Sample size accounted for more than $100 \%$ of the variance in the observed effect size.

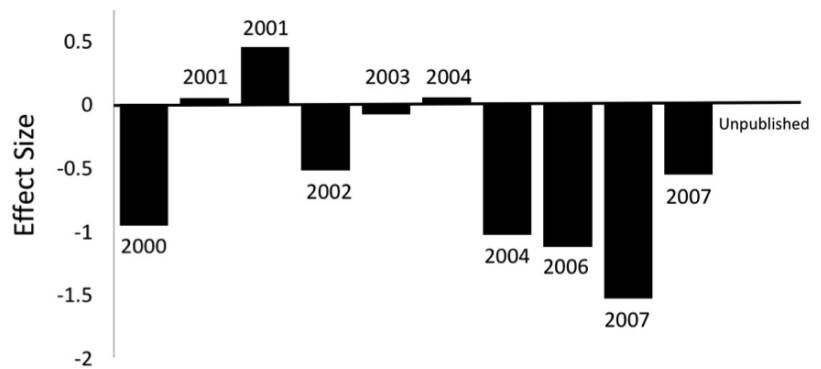

FIGURE 1. Effect size for interviewer ratings over time. Dates indicate year of publication; bars represent individual study effect size $(d)$; negative value indicates more positive reactions to FTF condition.

represents a more accurate or biased estimation of applicants' qualifications.

Applicant reactions were less favorable in technology-mediated interviews, possibly applicants' ability to impression manage is restricted. Because applicants are less able to impression manage in technology-mediated interviews, perceptions of unfairness and feelings of frustration occur. Applicant reactions may also be lower in technology-mediated interviews because they feel impersonal.

We also found that effect sizes for interviewer ratings were larger in field studies, bringing into question the external validity of interview research conducted in laboratories. Interviewees in laboratory studies are likely not as motivated to perform well or do not experience the pressure that comes with a job interview. Effect sizes for applicant

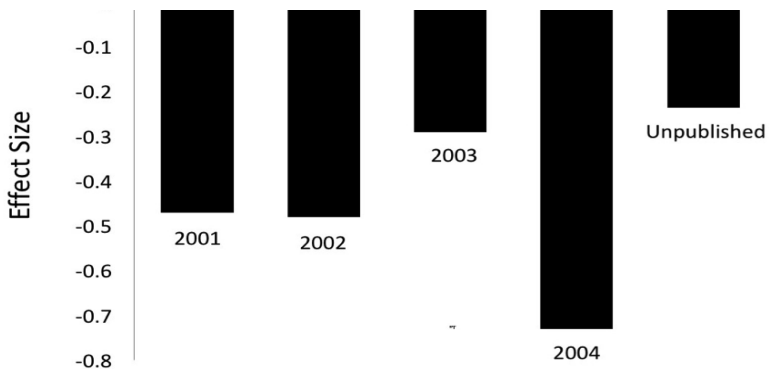

FIGURE 2. Effect size for applicant reactions over time. Dates indicate year of publication; bars represent individual study effect size $(d)$; negative value indicates more positive reactions to FTF condition.

reactions also differed across field and lab studies but in the opposite direction. Findings from lab studies may not generalize.

Although this research provides initial evidence that technology affects interviewer ratings and applicant reactions, there is still much to learn. Given the increasing use of technology in selection, and a troubling absence of research, a valuable opportunity exists for researchers to gain a better understanding of the technology-mediated interview process.

\section{Limitations}

A number of limitations are present in the current meta-analysis. First, this study included a small number of 
studies. When meta-analysis is based on a small number of studies, second-order sampling error occurs (Hunter \& Schmidt, 2004). Results should therefore be interpreted with caution. Despite the existence of second-order sampling error, the optimal method for aggregating findings is still meta-analysis, as narrative reviews of this literature would be more likely to lead to error (Schmidt, Hunter, Pearlman, \& Hirsh, 1985). Other meta-analyses with a similarly small number of studies have been published and successful in stimulating future research (e.g., Allen, Eby, Poteet, Lentz, \& Lima, 2004; Riketta, 2008).

Due to the small number of studies, ratings and reactions variables from individual studies were aggregated, such that our findings do not describe specific criterion constructs. The different types of technology-mediated interviews (e.g., video, telephone) were also combined. Further, of the few studies available, most were published between 2001-2004. The most recent publication was 7 years old. Considering the rate at which technology has changed, it is clear that we lack understanding of the modern interview. This type of limitation is inherent in meta-analyses; that is, results are limited by characteristics of the primary studies available.

\section{Research Issues and Recommendations}

Decades of research have generated a wealth of knowledge on interviews (Huffcutt \& Culbertson, 2010). The modern interview, however, introduces new technological factors and considerations; previous research may not generalize to technology-mediated interviews. Though several researchers (e.g., Anderson, 2003; Huffcutt \& Culbertson, 2010; Potosky, 2008) have called for research involving technology in the preemployment phase, the response has been inadequate. Below, we detail our recommendations for future research.

Define attributes of technology and identify their effect on outcomes. It is not sufficient to use the technology type (e.g., video and telephone) as a catchall predictor construct. Instead, we must define the psychological attributes of technologies. The purpose of discussing media in terms of attributes is to focus on the communication exchange process and understand how the medium may contribute or detract from the process (Potosky, 2008). We echo the call made from other authors (e.g., Adler, Arthur, Morelli, Potosky, \& Tippins, 2016; Potosky, 2008; Stone, Lukaszewski, Stone-Romero, \& Johnson, 2013; Strohmeier, 2007) to develop a comprehensive conceptual framework. Potosky (2008) developed a strong foundation for such a framework from which a more holistic model that includes systematic categorization of various technologies can be built.

Evaluate validity. The question of whether differences in ratings reflect an increase or decrease in the validity of the interview should be the focus of future research.
The removal of cues could be beneficial; without visual cues, some known biases, such as physical attractiveness, are removed (Behrend, Toaddy, Thompson, \& Sharek, 2012). Conversely, lower ratings could reflect a decrease in validity, as important verbal and nonverbal cues used to make ratings are removed and could lead to an incomplete evaluation of skills and qualifications. There is a need to understand how technological attributes influence the way that interviewers make ratings and whether those ratings are more or less accurate. This also requires an investigation of other constructs that may contaminate measurement (e.g., technological savvy) and whether the interviewer rating process is equivalent across interview medium.

Assess applicants'subjective perceptions and individual differences. Applicants may vary in their perceptions of security, media richness, or privacy of a technology (Chapman et al., 2003; Kiesler, Siegel, \& McGuire, 1984). Perceptions of media richness (i.e., the amount of social cues available; Daft \& Lengel, 1986) have been shown to influence key criteria (Chapman \& Webster, 2001). Evidence for individual differences in reactions to technological interviews also exists (Stone et al., 2013). Individuals who are high self-monitors are more likely to perceive telephone interviews as unfair (Chapman et al., 2003). Thus, a consideration of how individual differences and applicant perceptions of interview medium influence outcomes is warranted.

Evaluate fairness. All interviews should be fair and unbiased. The use of technology has the potential to adversely affect members of protected groups or unintentionally decrease the diversity of the applicant pool. Evidence for age, race, and socioeconomic differences in access to the Internet has been provided in a number of studies (Russell, 2007; Stone et al., 2013). We must determine if interview medium differentially predicts interview performance and job performance for members of protected classes.

Consider moderators. Past research demonstrates that interview characteristics (Peeters \& Lievens, 2006) and context (Morgeson \& Ryan, 2009) influence interviewer ratings and applicant reactions (Anderson, 2003). Question type, instructions, scale format, and structure can all influence the validity of interviewer ratings (Maurer, 2002). Interviewer expertise and interviewee experience may also moderate these relationships.

\section{CONCLUSION}

This meta-analysis demonstrates that interviewer ratings and applicant reactions can be influenced by technological characteristics. Electronic communication media can change behavior and perceptions. The small number of studies identified for this meta-analysis illustrates a void of research on technology-mediated interviews. Moreover, many of the findings are outdated and may not generalize to modern technologies. To fully understand the role of tech- 
nology in interviews, future research is needed in the areas we have outlined.

\section{REFERENCES}

Adler, S., Arthur, W., Jr., Morelli, N. (chair), Potosky, D., \& Tippins, N. (2016, April). Developing a conceptual model of technology applied to I-O psychology. Panel discussion presented at the 31 st annual conference of The Society for Industrial and Organizational Psychology, Anaheim, CA.

Allen, T. D., Eby, L. T., Poteet, M. L., Lentz, E., \& Lima, L. (2004). Career benefits associated with mentoring for protégés: A meta-analysis. Journal of Applied Psychology, 89, 127-136.

Anderson, N. (2003). Applicant and recruiter reactions to new technology in selection: A critical review and agenda for future research. International Journal of Selection and Assessment, 11, 121-136.

Andrews, L., Klein, S. R., Forsman, J., \& Sachau, D. (2013). It's easy being green: Benefits of technology-enabled work. In A. H. Huffman \& S. R. Klein (Eds.) Green organizations: Driving change with I-O psychology (p. 300-322). New York, NY: Routledge.

Barrick, M. R., Dustin, S. L., Giluk, T. L., Stewart, G. L., Shaffer, J. A., \& Swider, B. W. (2012). Candidate characteristics driving initial impressions during rapport building: Implications for employment interview validity. Journal of Occupational and Organizational Psychology, 85(2), 330-352.

Barrick, M. R., Shaffer, J. A., \& DeGrassi, S. W. (2009). What you see may not be what you get: Relationships among self-presentation tactics and ratings of interviews and job performance. Journal of Applied Psychology, 94(6), 1394-1411.

Bauer, T. N., Truxillo, D. M., Mack, K., \& Costa, A. B. (2011). Applicant reactions to technology-based selection: What we know so far. In N. T. Tippins \& S. Adler (Eds.), Technology-enhanced assessment of talent (pp. 190223). San Francisco, CA: Jossey-Bass.

*Bauer, T. N., Truxillo, D. M., Paronto, M. E., Weekley, J. F., \& Campion, M. A. (2004). Applicant reactions to different selection technology: Face-to-face, interactive voice response, and computer-assisted telephone screenings. International Journal of Selection and Assessment, 12(1-2), 135-148.

Behrend, T.S., \& Thompson, L.F. (2013). Combining I-O psychology and technology for an environmentally sustainable world. In A. H. Huffman \& S. R. Klein (Eds.) Green organizations: Driving change with I-O psychology (pp. 300-322). New York, NY: Routledge.

Behrend, T., Toaddy, S., Thompson, L. F., \& Sharek, D. J. (2012). The effects of avatar appearance on interviewer ratings in virtual employment interviews. Computers in Human Behavior, 28(6), 2128-2133.

Borkenau, P., \& Liebler, A. (1995). Observable attributes as manifestations and cues of personality and intelligence. Journal of Personality, 63, 1-25.
*Blackman, M. C. (2002). The employment interview via telephone: Are we sacrificing accurate personality judgments for cost efficiency? Journal of Research in Personality, 36(3), 208-223.

*Chapman, D. S., \& Rowe, P. M. (2001). The impact of videoconference technology, interview structure, and interviewer gender on interviewer evaluations in the employment interview: A field experiment. Journal of Occupational and Organizational Psychology, 74(3), 279-298.

*Chapman, D. S., \& Rowe, P. M. (2002). The influence of videoconference technology and interview structure on the recruiting function of the employment interview: $A$ field experiment. International Journal of Selection and Assessment, 10(3), 185-197.

Chapman, D. S., Uggerslev, K. L., Carroll, S. A., Piasentin, K. A., \& Jones, D. A. (2005). Applicant attraction to organizations and job choice: A meta-analytic review of correlates of recruiting outcomes. Journal of Applied Psychology, 90(5), 928-944.

*Chapman, D. S., Uggerslev, K. L., \& Webster, J. (2003). Applicant reactions to face-to-face and technologymediated interviews: A field investigation. Journal of Applied Psychology, 88(5), 944-953.

Chapman, D. S., \& Webster, J. (2001). Rater correction processes in applicant selection using videoconference technology: The role of attributions. Journal of Applied Social Psychology, 31(12), 2518-2537.

Daft, R. L., \& Lengel, R. H. (1986). Organizational information requirements, media richness and structural design. Management Science, 32, 554-571. doi: 10.1287/mnsc.32.5.554

DeGroot, T., \& Gooty, J. (2009). Can nonverbal cues be used to make meaningful personality attributions in employment interviews? Journal of Business and Psychology, 24(2), 179-192.

DeGroot, T. \& Motowidlo, S.J. (1999). Why visual and vocal cues can affect interviewers' judgments and predict job performance. Journal of Applied Psychology, 84(6), 986-993.

Doherty-Sneddon, G., Anderson, A., O'Malley, C., Langton, S., Garrod, S., \& Bruce, V. (1997). Face-to-face and video-mediated communication: A comparison of dialogue structure and task performance. Journal of Experimental Psychology: Applied, 3(2), 105-125.

Ellis, A. P., West, B. J., Ryan, A. M., \& DeShon, R. P. (2002). The use of impression management tactics in structured interviews: a function of question type? Journal of Applied Psychology, 87(6), 1200-1208.

Feiler, A. R., \& Powell, D. M. (2016). Behavioral expression of job interview anxiety. Journal of Business and Psychology, 31, 155-171.

*Fullwood, C. (2007). The effect of mediation on impression formation: A comparison of face-to-face and videomediated conditions. Applied Ergonomics, 38(3), $267-$ 273.

Giordano, G., Stoner, J., DiGangi, P. \& Lewis, C. (2010). Media synchronicity and stress in online interview settings. Media Synchronicity and Stress in Online 
Interview Settings. SIGHCI 2010 Proceedings. Paper 5. http://aisel.aisnet.org/sighci2010/5

Gilmore, D.C., \& Ferris, G.R. (1989). The effects of applicant impression management tactics on interviewer judgments. Journal of Management, 15(4), 557-564.

Guchait, P., Ruetzler, T., Taylor, J., \& Toldi, N. (2014). Video interviewing: A potential selection tool for hospitality managers - A study to understand applicant perspective. International Journal of Hospitality Management, 36, 90-100.

Hausknecht, J. P., Day, D. V., \& Thomas, S. C. (2004). Applicant reactions to selection procedures: An updated model and meta-analysis. Personnel Psychology, 57(3), 639-683.

Herman, J. B. (1977). Mixed-mode data collection: Telephone and personal interviewing. Journal of Applied Psychology, 62(4), 399-404.

Horn, R. G., \& Behrend, T. S. (2016, April). Video killed the interview star: Does picture-in-picture affect interview performance? Poster presented at the 31st Annual Conference of the Society for Industrial and Organizational Psychology, Anaheim, CA

Howard, J. L., \& Ferris, G. R. (1996). The employment interview context: Social and situational influences on interviewer decisions. Journal of Applied Social Psychology, 2, 112-136.

Huffcutt, A. I., \& Culbertson, S. S. (2010). Interviews. In S. Zedeck (Ed.), APA handbook of industrial and organizational psychology Vol 2: Selecting and developing members for the organization (pp. 185203). Washington, DC: American Psychological Association.

Hunter, J. E., \& Schmidt, F. L. (2004). Methods of metaanalysis: Correcting error and bias in research findings. Newbury Park, CA: Sage.

Ingold, P. V., Kleinmann, M., König, C. J., \& Melchers, K. G. (2015). Shall we continue or stop disapproving of selfpresentation? Evidence on impression management and faking in a selection context and their relation to job performance. European Journal of Work and Organizational Psychology, 24(3), 420-432.

Kiesler, S. Siegel, J., \& McGuire, T.W. (1984). Social psychological aspects of computer-mediated communication. American Psychologist, 39(10), 11231134.

Larsen, R. J., \& Shackelford, T. K. (1996). Gaze avoidance: Personality and social judgments of people who avoid direct face-to-face contact. Personality and Individual Differences, 21, 907-917.

Leary, M. R. (1983). Understanding social anxiety. Beverly Hills, CA: Sage.

Leary, M. R., \& Kowalski, R. M. (1990). Impression management: A literature review and a two-component model. Psychological Bulletin, 107, 34-47.

Maruping, L. M., \& Agarwal, R. (2004). Managing team interpersonal process through technology: A tasktechnology fit perspective. Journal of Applied Psychology, 89, 975-990.

Maurer, S. D. (2002). A practitioner-based analysis of interviewer job expertise and scale format as context factors in situational interviews. Personnel Psychology, 55, 307-327.

Morgeson, F. P. \& Ryan, A. M. (2009). Reacting to applicant perspectives research: What's next? International Journal of Selection and Assessment, 17, 431-437.

Peeters, H. \& Lievens, F. (2006). Verbal and nonverbal impression management tactics in behavior description and situational interviews. International Journal of Selection and Assessment, 14, 206-222.

Posthuma, R. A., Morgeson, F. P., \& Campion, M. A. (2002). Beyond employment interview validity: A comprehensive narrative review of recent research and trends over time. Personnel Psychology, 55, 1-81.

Potosky, D. (2008). A conceptual framework for the role of the administration medium in the personnel assessment process. Academy of Management Review, 33(3), 629648.

Powers, S. R., Rauh, C., Henning, R. A., Buck, R. W., \& West, T. V. (2011). The effect of video feedback delay on frustration and emotion communication accuracy. Computers in Human Behavior, 27(5), 1651-1657.

Riketta, M. (2008). The causal relation between job attitudes and performance: A meta-analysis of panel studies. Journal of Applied Psychology, 93, 472-481.

Rosenfeld, P. (1997). Impression management, fairness, and the employment interview. Journal of Business Ethics, 16(8), 801-808.

Russell, D. P. (2007). Recruiting and staffing in the electronic age: A research-based perspective. Consulting Psychology Journal: Practice and Research, 59, 91-101. doi:10.1037/1065-9293.59.2.91

Rynes, S. L., \& Connerley, M. L. (1993). Applicant reactions to alternative selection procedures. Journal of Business and Psychology, 7, 261-277.

Schmidt, F. L., Hunter, J. E., Pearlman, K., \& Hirsh, H. R. (1985). Forty questions about validity generalization and meta-analysis. Personnel Psychology, 38, 697-798.

Schmidt, F. L., \& Le, H. (2004). Software for the HunterSchmidt meta-analysis methods [software]. lowa City, IA: Tippie College of Business, University of lowa.

Shermis, M. D., \& Lombard, D. (1998). Effects on computerbased test administration on test anxiety and performance. Computers in Human Behavior, 14, 111123.

*Silvester, J., \& Anderson, N. (2003). Technology and Discourse: A Comparison of Face-to-face and Telephone Employment Interviews. International Journal of Selection and Assessment, 11(2-3), 206-214.

*Silvester, J., Anderson, N., Haddleton, E., CunninghamSnell, N., \& Gibb, A. (2000). A cross-modal comparison of telephone and face-to-face selection interviews in graduate recruitment. International Journal of Selection and Assessment, 8(1), 16-21.

Stevens, C. K., \& Kristof, A. L. (1995). Making the right impression: A field study of applicant impression management during job interviews. Journal of Applied Psychology, 80(5), 587-606.

Stewart, G. L., Dustin, S. L., Barrick, M. R., \& Darnold, T. 
C. (2008). Exploring the handshake in employment interviews. Journal of Applied Psychology, 93(5), 11391146.

Stone, D. L., Lukaszewski, K. M., Stone-Romero, E. F., \& Johnson, T. L. (2013). Factors affecting the effectiveness and acceptance of electronic selection systems. Human Resource Management Review, 23, 50-70.

*Straus, S. G., Miles, J. A., \& Levesque, L. L. (2001). The effects of videoconference, telephone, and face-toface media on interviewer and applicant judgments in employment interviews. Journal of Management, 27(3), 363-381.

Strohmeier, S. (2007). Research in e-HRM: Review and implications. Human Resource Management Review, 17, 19-37.

Swider, B. W., Barrick, M. R., Harris, T. B., \& Stoverink, A. C. (2011). Managing and creating an image in the interview: the role of interviewee initial impressions. Journal of Applied Psychology, 96(6), 1275-1288.

*Thompson, L. F., Pearce, B. J., \& Behrend, T. S. (n.d.) Conducting job interviews online removes the selfmonitoring advantage: The role of self-monitoring during face-to-face and online job interviews. Unpublished manuscript.

*Thompson, L. F., \& Surface, E. A. (2006). Assessment from afar: Comparing telephonic and face-to-face foreign language speaking proficiency interviews. Paper presented at the 21st annual meeting of the Society for Industrial and Organizational Psychology, Dallas, TX.

*Thompson, L. F., \& Surface, E. A., \& Whelan, T. J. (2007, April). Examinees' reactions to computer-based versus telephonic oral proficiency interviews. Paper presented at the 22nd annual conference of the Society of Industrial and Organizational Psychology, New York, NY.

Toldi, N. L. (2011). Job applicants favor video-interviewing in the candidate-selection process. Employment Relations Today, 38(3), 19-27.

Walther, J.B. (2012). Interaction through technical lenses: Computer-mediated communication and language. Journal of Language and Social Psychology, 31, 397414.

Wegge, J. (2006). Communication via videoconference: Emotional and cognitive consequences of affective personality dispositions, seeing one's own picture, and disturbing events. Human-Computer Interaction, 21(3), 273-318.

RECEIVED 2/1/16 ACCEPTED 6/17/16 